\title{
The power of the mind to influence other minds by the will-force in the presence of consciousness leading to super-consciousness
}

\author{
Dhananjay Pal \\ Ex-Dean of research, Pharmacy College, Bengal School of Technology, Sugandha-Delhi Road, Chuchura, Dist.-Hooghly, West Bengal, \\ INDIA, PIN-712 102
}

Email address:

dhananjay.pal123@gmail.com, paldhananjay46@yahoo.com

\section{To cite this article:}

Dhananjay Pal. The Power of the Mind to Influence other Minds by the Will-Force in the Presence of Consciousness Leading to Super-Consciousness. American Journal of Modern Physics. Vol. 3, No. 6, 2014, pp. 261-279. doi: 10.11648/j.ajmp.20140306.21

\begin{abstract}
A single field emerged at the origin of the universe, already containing within itself the blueprint of the physical universe. The primordial single field triggered the onset of the universe. Most physicists believe that a single super-force dominated the first instants of creation. Scientists have arrived at a simple but decisive conclusion that consciousness is very much a part of the universe, like other objects. Our consciousness model involving thought-carrying particle (TCP), thought retaining particle (TRP) and thought force $\left(\mathrm{T}_{\mathrm{F}}\right)$ signifies the existence of universal consciousness that exists along with the universe. This universal consciousness is a functional state of the universal mind (UM). This UM is evolved at the Big Bang from void. The UM is constituted by these TCP and TRP in the inherent presence of thought force $\left(\mathrm{T}_{\mathrm{F}}\right)$. Thought force $\left(\mathrm{T}_{\mathrm{F}}\right)$ is an expression of universal consciousness. The Thought force $\left(\mathrm{T}_{\mathrm{F}}\right)$ being the primordial quantum field functions as the original super-force. $\mathrm{T}_{\mathrm{F}}$ being the original super-force functions as the origin of all the fundamental fields. TCP is the carrier of thought force $\left(\mathrm{T}_{\mathrm{F}}\right)$ that, in turn, appears to be the origin of all the fields. The quantized energy $\left(\varepsilon_{T}\right)$ of TCP is responsible to cause the universal consciousness as well as the cosmic microwave background radiation temperature. The individual consciousness owes its origin to the universal consciousness created by the same $\varepsilon_{T}$. The same $\varepsilon_{T}$ is the energy responsible for generating thought force $\left(\mathrm{T}_{\mathrm{F}}\right)$. $\mathrm{T}_{\mathrm{F}}$ being an expression of the universal consciousness is applicable to any inanimate object as well as to any biological system (having thinking ability). The $\mathrm{T}_{\mathrm{F}}$ exerts its functions both in vitro and in vivo. These TCP, TRP and the thought force $\left(\mathrm{T}_{\mathrm{F}}\right)$ in vitro and thought force $\left(\mathrm{T}_{\mathrm{F}}\right)$ in vivo can address the power of the mind to influence other minds by the will-force in the presence of consciousness leading to super-consciousness.
\end{abstract}

Keywords: Void, Cosmic Microwave Background Radiation (CMBR), Universal Mind (UM), Thought Force ( $\left.\mathrm{T}_{\mathrm{F}}\right)$, Though-Carrying Particle (TCP), Thought Retaining Particle (TRP), Quantized Energy $\left(\varepsilon_{T}\right)$ of TCP

\section{Introduction}

In Eastern philosophical traditions, consciousness is intrinsic to the universe, whereas in most Western views, consciousness is extrinsic, emerging from complex computation. How can these views be reconciled?

It is most relevant and important to indicate the names of various eminent physicists like Erwin Schrödinger, Eugene Wigner, Brian Josephson, John Wheeler, Roger Penrose, Henry P Stapp, Freeman J. Dyson, Paul Davies, David Bohm, Basil Hiley, Fritjof Capra, Fred Alan Wolf and Amit Goswami who have addressed the inclusion of consciousness in their work. Consciousness is to be taken into account.

\subsection{Evolution of Universe with Universal Consciousness}

In contrast to the usual linear sequence of matter, body, life, brain, mind, consciousness, here the proposed cyclic sequence is first universal consciousness (a functional state of the universal mind), and then matter, body, life, brain, and regeneration of mind and consciousness. The evolution of life with mind and consciousness is possible purely due to the inherent existence of universal consciousness which exists along with the universe. The human nervous system is evolved to provide an appropriate material structure to individualize the universal consciousness, a characteristic of reality, pervading all manifestations.

Consciousness model of Pal et al [1-3] involving TCP, 
TRP and thought force $\left(\mathrm{T}_{\mathrm{F}}\right)$ signifies the existence of universal consciousness that exists along with the universe. Pal et al [3] showed that this universal consciousness is a functional state of Universal Mind (UM). Pal et al [3] explained that the UM is evolved at the Big Bang from the eternal Void. This Void, in turn, is the source of infinite energy. And this UM is a finer matter. The individual mind being a constituent of the UM is also a finer matter. The constituents of the UM and individual mind are the same. The ultimate constituents of matter and mind are the same as both mind and matter are aspects of one fundamental reality, which is called UM. The brain is the mediating link or interface between the individual mind and body.

Pal et al [3] explained that the constituents of the UM are the ultimate constituents of matter itself as everything in this universe is a manifestation of this UM. Pal et al [3] expressed that the UM is constituted by these TCP and TRP in the inherent presence of thought force $\left(\mathrm{T}_{\mathrm{F}}\right)$. Pal et al $[1,3]$ further explained that the ultimate constituents of matter and mind are these TCP and TRP in the inherent presence of thought force $\left(\mathrm{T}_{\mathrm{F}}\right)$ in vitro and thought force $\left(\mathrm{T}_{\mathrm{F}}\right)$ in vivo.

Physicists determined that underlying quantum fields give birth to elementary particles. Bhaumik [4] mentioned that Frank Wilczek pointed out, "In quantum field theory, the primary elements of reality are not individual particles, but underlying fields. Thus, for example, all electrons are but excitations of an underlying field, naturally called electric field". The same holds true for all the fundamental particles of which matter is made.

The existence of matter depends on the existence of force and vice versa. TCP cannot exist without TRP and vice versa. Many physicists believe that unifying all the forces, including gravity, into a single theory would require a phenomenon called super-symmetry. With super-symmetry, every fermion would have a boson twin, and vice-versa. The thought force $\left(\mathrm{T}_{\mathrm{F}}\right)$ is carried by the TCP in the presence of its super-symmetrical partner TRP. TCP that behaves like boson should accompany its super-symmetrical partner TRP that functions like fermion in the generalized simpler way. It is to be noted that these TCP and TRP function like wavicle: wave-particle duality.

\section{Thought Force}

Pal et al [1,3] and Pal [5] explained the existence of thought force $\left(\mathrm{T}_{\mathrm{F}}\right)$. Thought force $\left(\mathrm{T}_{\mathrm{F}}\right)$, an expression of the universal consciousness, is the primordial quantum field that, in turn, functions as the primary unified field. This $\mathrm{T}_{\mathrm{F}}$ being an expression of the universal consciousness is applicable to any inanimate object as well as to any biological system (having thinking ability). Thus the $\mathrm{T}_{\mathrm{F}}$ being an expression of the universal consciousness exerts its functions both in vitro and in vivo.

Physicists determined that underlying quantum fields give birth to elementary particles. Pal [5] expressed that the thought force $\left(\mathrm{T}_{\mathrm{F}}\right)$ is the primordial quantum field. Thought force $\left(\mathrm{T}_{\mathrm{F}}\right)$ being the primordial quantum field functions as the primary unified field. Thought force $\left(T_{F}\right)$ being the primordial quantum field gives birth to TRP that appears to be the origin of all the matter particles. TCP is the carrier of thought force $\left(\mathrm{T}_{\mathrm{F}}\right)$ that, in turn, appears to be the origin of all the fields. TCP thus appears to be the origin of all the field particles.

In a purpose to involve both the non-living and living systems of the world, Pal [5] has shown the existences of these TCP, TRP and thought force $\left(\mathrm{T}_{\mathrm{F}}\right)$ in vitro and thought force $\left(\mathrm{T}_{\mathrm{F}}\right)$ in vivo. Anyone can call this TCP by any other name, but as the highly developed living system will have to be evolved in the universe in the long run and as the thought of highly developed living system appears to be a kind of force to be called the thought force $\left(\mathrm{T}_{\mathrm{F}}\right)$ in vivo, we considered it is wise to call it as TCP. Further, as the universe exists along with the universal consciousness that, in turn, is created by the quantized energy $\left(\varepsilon_{T}\right)$ of TCP, we had to use the term TCP.

Pal (5) expressed that the non-living system of the world is governed by the thought force $\left(\mathrm{T}_{\mathrm{F}}\right)$ in vitro and this Thought force $\left(\mathrm{T}_{\mathrm{F}}\right)$ in vitro gives rise to $\mathrm{T}_{\mathrm{F}}$ (micro), $\mathrm{SNF}, \mathrm{EMF}, \mathrm{WNF}$, GF and $T_{F}$ (macro) where $T_{F}$ (micro) $=$ Thought force in microcosm, $\mathrm{SNF}=$ Strong nuclear force, $\mathrm{EMF}=$ Electromagnetic force, $\mathrm{WNF}=$ Weak nuclear force, $\mathrm{GF}=$ Gravitational force and $\mathrm{T}_{\mathrm{F}}$ (macro) $=$ Thought force in macrocosm. It is to be noted here that $\mathrm{T}_{\mathrm{F}}$ (micro) is a stronger force than the SNF and $\mathrm{T}_{\mathrm{F}}$ (macro) is a weaker force even than the GF.

Pal (5) also expressed that the living system of the world is governed by the thought force $\left(\mathrm{T}_{\mathrm{F}}\right)$ in vivo and this Thought force $\left(\mathrm{T}_{\mathrm{F}}\right)$ in vivo is a type of force that represents the biological 'thought' which is the action of mind. This 'thought' being a type of force controls the 'thought processes' involving the firing of neurons through the quantum mechanical activities of these TCP and TRP in the presence of consciousness. Consciousness in living organisms is a process which involves the quantum mechanical activities of these TCP and TRP, the ultimate constituents of any matter as well as any mind in the inherent presence of thought force $\left(\mathrm{T}_{\mathrm{F}}\right)$ in vitro and the thought force $\left(\mathrm{T}_{\mathrm{F}}\right)$ in vivo as indicated by Pal et al [3]. This consciousness, in turn, is the quantized energy $\left(\varepsilon_{T}\right)$ of TCP. The thought force $\left(\mathrm{T}_{\mathrm{F}}\right)$ in vivo is demonstrated in numerous experiments in which thought has an effect on a physical process (often known as mind over matter). This biological 'thought' is a type of force that can cause movement. Controlling movement through thought alone is observed in several experiments conducted by many scientists as indicated by $\mathrm{Pal}$ (5). These experiments thus signify the existence of thought force $\left(\mathrm{T}_{\mathrm{F}}\right)$ in vivo.

Pal [5] explained the existence of $\mathrm{T}_{\mathrm{F}}$ (micro) (= Thought force in microcosm). This $\mathrm{T}_{\mathrm{F}}$ (micro) is the strongest interaction (a new class of 'extra strong' interaction). It is stronger than SNF (Strong Nuclear Force).

Pal [5] has also shown the existence of $\mathrm{T}_{\mathrm{F}}$ (macro) (= Thought force in macrocosm). It is the "weakest force" which is much weaker even than the gravity. 


\subsection{Equation Expressing the Quantized Energy $\left(\varepsilon_{\mathrm{T}}\right)$ of TCP}

Pal et al [3] developed three different equations expressing the quantized energy ( $\varepsilon_{T}$ ) of TCP. The value of $\varepsilon_{T}$ in one of the three equations is shown below:

$$
\varepsilon_{\mathrm{T}}=4.384 \times 10^{-16} \mathrm{erg} \equiv 2.73 \times 10^{-4} \mathrm{eV} \equiv 2.73 \mathrm{~K} \cong \mathrm{CMBR}
$$$$
\text { temperature } \equiv 2.725 \mathrm{~K}
$$

This conversion of erg $\equiv \mathrm{eV} \equiv \mathrm{K}$ is given by Weisskopf [6] as follows:

$$
1 e r g \cong 0.6241807 \times 10^{12} \mathrm{eV} \text { and } 10^{-4} \mathrm{eV} \cong 1 \mathrm{~K}
$$

\subsection{CMBR Temperature is Due to ${ }^{\mathcal{E}_{T} \text {, the Quantized }}$ Energy of TCP}

Pal et al [3] expressed that the CMBR temperature is due to $\varepsilon_{T}$, the quantized energy of TCP where

$$
\begin{aligned}
& \mathcal{E}_{\mathrm{T}}=4.384 \times 10^{-16} \mathrm{erg} \equiv 2.73 \times 10^{-4} \mathrm{eV} \equiv 2.73 \mathrm{~K} \cong \mathrm{CMBR} \\
& \text { temperature } \equiv 2.725 \mathrm{~K}
\end{aligned}
$$

As per Pal et al [3], it is interesting to note that all of the three different equations ultimately give rise to the same result that is equivalent to the CMBR temperature. A sort of relationship is thus observed between the ${ }^{\mathcal{E}_{T}}$ and the CMBR temperature. This coincidence is thus signifying a probable role of TCP on the maintenance of CMBR temperature. Further, this coincidence is also signifying the existence of these TCP in the presence of TRP. TCP cannot exist without TRP and vice versa. The presence of TCP, TRP and Thought force $\left(\mathrm{T}_{\mathrm{F}}\right)$ in the universe is thus indicated and expressed mathematically. At present we are unable to explain when and how these TCP and TRP decoupled from the primordial cosmic soup.

Pal et al $[1,3]$ showed that the quantized energy $\left(\varepsilon_{T}\right)$ of TCP is responsible to cause the universal consciousness as well as the cosmic microwave background radiation temperature. The individual consciousness owes its origin to the universal consciousness created by the same $\varepsilon_{T}$. Ultimately this $\mathcal{E}_{T}$ represents universal consciousness. The existence of CMBR temperature indicates the existence of the TCP in the presence of TRP. The existence of TCP ensures the existence of the thought force $\left(\mathrm{T}_{\mathrm{F}}\right)$. Further, this $\mathrm{T}_{\mathrm{F}}$ being an expression of the quantized energy ( $\varepsilon_{T}$ ) of TCP exerts its functions both in vitro and in vivo.

\section{The Following Parameters are to be properly Defined and Interpreted, if Possible with Interrelation among Them}

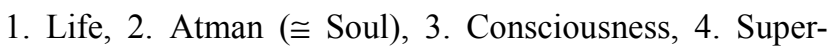
consciousness, 5. Mind, 6. Prâna, 7. Will-force/Will-power, 8.
Brain, 9. Body/Matter

\subsection{What is Life?}

Life is a state of flux that is being maintained by a typical form of energy which is nothing but the consciousness itself. Pal et al [3] and Pal [7] showed that the quantized energy $\left(\varepsilon_{T}\right)$ of TCP is responsible to cause the universal consciousness as well as the cosmic microwave background radiation temperature. The individual consciousness owes its origin to the universal consciousness created by the same $\varepsilon_{T}$. Pal et al [1,3] and Pal [7] explained that life may be defined as a state of functional manifestation of consciousness that, in turn, is the quantized energy ( $\left.\varepsilon_{T}\right)$ of TCP. This $\varepsilon_{T}$ represents universal consciousness.

Thus,

$$
\text { Life }=\mathrm{f}(\text { Consciousness })=\mathrm{f}\left(\boldsymbol{E}_{T}\right)
$$

where $\varepsilon_{T}=$ quantized energy of the TCP $=4.384 \times 10^{-16} \mathrm{erg}$.

$$
\varepsilon_{T}=h v_{T}=h c / \lambda_{T}=4.384 \times 10^{-16} \mathrm{erg}
$$

where $\varepsilon_{T}=$ quantized energy of the TCP $=4.384 \times 10^{-16} \mathrm{erg}$,

$$
v_{T}=\text { frequency of the TCP }=\varepsilon_{T} / h=66.12 \times 10^{9} \mathrm{~Hz} .=
$$
$66.12 \mathrm{GHz}$,

$$
\begin{aligned}
& \mathrm{h}=\text { Planck's quantum constant }=6.63 \times 10^{-27} \mathrm{erg} . \mathrm{sec}, \\
& \mathrm{c}=\text { free-space velocity of light }=3 \times 10^{10} \mathrm{~cm} / \mathrm{sec} \\
& \lambda_{T}=\text { wave-length of the } \mathrm{TCP}=0.4537 \mathrm{~cm} .
\end{aligned}
$$

\subsection{What is Consciousness?}

Psychologists, neuroscientists, philosophers, and other professionals continue to engage in an ongoing debate as to what consciousness means. In reality, we may never know. Is it a product of the biological and classical physical interactions of the human brain; or is it something more fundamental, perhaps electromagnetic, or the result of quantum physics principles that we don't yet fully understand? Could it be something even more profound than that -something beyond the scope of science and physics, any kind of physics, for us to understand?

According to the ancient Vedanta, consciousness is not an emergent property of matter that comes into existence only through the functioning of the human nervous system. Instead, consciousness is a characteristic of reality, pervading all manifestations. This unbounded field of nature's universal consciousness is not limited to an individual consciousness. From this viewpoint, the role of the human nervous system is to provide an appropriate material structure to individualize the universal consciousness. It appears that inanimate matter itself cannot generate consciousness without the inherent existence of universal consciousness.

Pal et al [2] explained, "Consciousness is the realization of existence, and there are as many states of consciousness as there are states of existence. Every living being has a 
consciousness of its own depending on complexity of the brain and the activity of the viable numbers of TCP in the presence of TRP; and the state of its consciousness changes every moment of time. Consciousness is the perception of the relation it bears to things and as this relation changes, consciousness changes its character. Consciousness itself does not change; it only moves up and down on the 'scale of the realization' of existence through the 'sub-conscious', 'conscious' and 'super-conscious' states". There is another term called unconscious state. The most usual unconscious state is sleep. A deeper form of unconsciousness is called a coma.

\subsection{Possible Relation of Consciousness with Mind: Possible Relation of Animate with Inanimate Through Consciousness}

Modern scientists have not even been able to arrive at a consensus on what should be a definition of the totality of consciousness. The brain is intricately linked to the process of consciousness and consciousness is thought to be a phenomenon of the mind.

It appears that

$$
\text { Consciousness }=\mathrm{f}(\operatorname{mind})
$$

Consciousness is the functional state of mind. Presence of consciousness signifies the presence of mind and vice versa.

It is apparent that

$$
\text { Animate } \neq \text { Inanimate }
$$

Three critical factors which distinguish life from nonliving are consciousness, metabolism and reproduction. (4):

In a gross presentation, we can express from the equation

$$
\text { Animate }- \text { Consciousness }=\text { Inanimate }
$$

Scientists would have to define and characterize consciousness properly. We should have the proper knowledge about the exact characteristics of consciousness in order to address many present day scientific enigmas.

\subsection{Consciousness may be defined as the 'Self-Organized' Capability of any Living Being to Activate TCP and TRP}

Pal et al [3] expressed that consciousness may be defined as the 'self-organized' capability of any living being to activate TCP and TRP, the ultimate constituents of mind and matter and to exert its functions. What can generate, maintain and activate TCP and TRP is called animate having 'active consciousness' and what cannot is called inanimate, i.e., devoid of active consciousness. As anything inanimate does neither have the power to activate the TCP and TRP nor have the capability to catalyze the activity of TCP and TRP, so it cannot generate consciousness. On the contrary, anything animate has the 'self-organized' power to generate, activate and catalyze the activity of TCP and TRP in order to generate and maintain consciousness along with the vital living force. Prigogine et al [8] explained "Self-Organization in NonEquilibrium Systems".

Consciousness in living organisms is a process which involves the quantum mechanical activities of these TCP and TRP, the ultimate constituents of any matter as well as any mind in the inherent presence of thought force $\left(\mathrm{T}_{\mathrm{F}}\right)$ in vitro and the thought force $\left(\mathrm{T}_{\mathrm{F}}\right)$ in vivo as indicated by Pal et al $[1$, 3]. And these TCP and TRP govern the activities of neurons (not the other way round). Neurons are simply the equipments used to generate consciousness and awareness. The consciousness itself is functioning as an inter-linking agent between the animate and inanimate through the quantum mechanical activities of these TCP and TRP indicated by Pal et al [3].

\section{Existence of Universal Consciousness:}

Pal et al [3] and Pal [7] showed the existence of universal consciousness and explained that the quantized energy $\left(\varepsilon_{T}\right)$ of TCP is responsible to cause the universal consciousness as well as the cosmic microwave background radiation temperature. The individual consciousness owes its origin to the universal consciousness created by the same ${ }^{\varepsilon_{T}}$.

Pal et al [3] have expressed that according to the modern physicists, the universe is the summation of fields, particles, space-time continuum, dark matter, dark energy, void and all the known and unknown parameters of the universe along with all its inhabitants (with or without consciousness), although the universe is always expanding.

The method of integration indicates that

$$
\int d x=x+c
$$

where $\mathrm{c}=\mathrm{a}$ constant. Is there any mathematical fallacy if we like to use 'universe' in the place of ' $x$ ' here? If we at all theoretically like to apply the same method of integration to the whole universe itself, we will have to arrive at

$$
\int \mathrm{d}(\text { universe })=\text { universe }+\mathrm{c}
$$

where universe $=$ universe with all its known and unknown parameters as well as its inhabitants (with or without consciousness) and $\mathrm{c}=\mathrm{a}$ constant. The constituents of the universe are fields, particles, space-time continuum, dark matter, dark energy, void, all its inhabitants (with or without consciousness) and all the other unknown parameters of the universe that we have not yet faced. We simply propose to apply the method of integration theoretically over the universe as a whole with all its known and unknown parameters and all the inhabitants (with or without consciousness). If we at all theoretically like to do so, we will mathematically arrive at a constant.

What is this constant here? It is our opinion that this constant is the universal consciousness that exists throughout the universe in the form of universe wide web (uww) 
covering fields, particles, space-time continuum, dark matter, dark energy, void and all its known and unknown parameters along with all its inhabitants (with or without consciousness). This universal consciousness is to be taken into account, but usually ignored.

Nelson [9], Director of Global Consciousness Project, has observed through the experimentation that coherent consciousness creates order in the world; and subtle interactions link us with each other and the Earth. When human consciousness becomes coherent and synchronized, the behavior of random systems may change. Quantum event based random number generators (RNGs) produce completely unpredictable sequences of zeroes and ones. But when a great event synchronizes the feelings of millions of people, our network of RNGs becomes subtly structured. The probability is less than one in a billion that the effect is due to chance. The evidence suggests an emerging noosphere, or the unifying field of consciousness described by sages in all cultures. This evidence signifies and proves the existence of universal consciousness.

The existence of universal consciousness is explained by Radin [10] through experimentation as it is expressed in his book: "The Conscious Universe: The Scientific Truth of Psychic Phenomena". Further, Consciousness, not matter, is the ground of all existence, declares University of Oregon physicist Goswami through his published (1993) book, "The Self-Aware Universe: How Consciousness Creates the Material World".

As per Penrose [11], consciousness is a part of the universe. Van De Bogart [12] explained, "Since consciousness is a part of the universe it then follows that all consciousness, and the universe, are of the same matrix of energy fields".

Many physicists agree with the idea that consciousness is non-local, fundamental in the universe and consciousness is very much a part of the universe, like other objects. It is to be noted that $\mathcal{E}_{T}$, the quantized energy of TCP represents universal consciousness.

The entire Universe or the particles in it are 'connected' through the existence of the quantum mechanical activities of these TCP in the presence of TRP. Pal et al [3] explained that the universe exists along with the universal consciousness. This universal consciousness functions as a universe wide web (uww) covering the universe as a whole with all its parameters (including void) and inhabitants (with or without consciousness). In this picture, uww of consciousness, quantum concepts like wave particle dualism, position momentum uncertainty, nonlocality and concept of unified field become somewhat understandable as all the entities of this universe are interlinked and intertwined. In this picture, the universal consciousness replaces ether of yesteryears and contains the whole of the universe in its fold.

Consciousness in living organisms is a process which involves the quantum mechanical activities of these TCP and TRP, the ultimate constituents of any matter as well as any mind in the inherent presence of thought force (TF) in vitro and the thought force (TF) in vivo as indicated by Pal et al [3].

The 'spooky action-at-a-distance' is built in nature through the existence of the quantum mechanical activities of these TCP in the inherent presence of TRP. The spooky non-local correlations-at-a-distance might evidence a Holy Ghost at work through the existence of the quantum mechanical activities of these TCP and TRP, the ultimate constituents of any matter as well as any mind in the inherent presence of thought force (TF) in vitro and the thought force $(\mathrm{TF})$ in vivo as indicated by Pal et al [3].

\subsection{Consciousness in Short}

Functional state of mind $\equiv$ Consciousness

Functional state of the Universal Mind $\equiv$ Universal consciousness

Consciousness is a type of energy.

Quantized energy $\left(\mathcal{E}_{T}\right)$ of TCP $=$ Universal consciousness.

Individual consciousness owes its origin to the universal consciousness created by the same $\varepsilon_{T}$.

Ultimately this $\varepsilon_{T}$ represents universal consciousness.

\section{What is the Exact Definition of Mind? What is Mind}

We observe a great controversy concerning the exact definition of mind. There are two apparently opposite views: one is the substantial view and the other is the functional view.

In the substantial view, the mind is a type of substance. Mind is a finer matter having an autonomous existence. Mind is a single entity, perhaps having its base in the brain but distinct from it. In its most extreme form as in the Indian Upanishads and Vedanta, the mind is not only a finer matter but also it is an entity wholly separate from the body, in fact a manifestation of the soul, which will survive the body's death in the form of the spiritual body or mental body [called Linga Sharira or Sukshma Sharira in Sanskrit] as expressed by Vivekananda [13] who indicated that this mental body bears all the mental impressions. This mental body is also called 'spirit'.

In the functional view, the mind is closely related to the functions of the brain and can have no autonomous existence beyond the brain, nor can they survive its death. In this view, mind is a 'state' created by the activities of the brain with other parts of the nervous system as it is indicated by cognitive neuro-scientists and Artificial Intelligence (AI) scientists. According to them 'minds are simply what brains do'. In this functional view, mind is a subjective manifestation of consciousness: the human brain's ability to be aware of its own existence. The concept of the mind is therefore a means by which the conscious brain understands its own operations.

The modern cognitive neuroscientists generally accept the fact that the "mind" is not an isolated entity and the mind is a state created by the activities of brain with other parts of the nervous system (CNS, PNS along with ANS). Although the mind is generally accepted to be an abstract having no spatial 
location or public observability, yet it is a type of fine matter according to the ancient Indian Upanishads and Vedanta. The Vedanta indicates that the universe exists along with the universal consciousness. Pal et al $[1,3]$ explained that this universal consciousness is a functional state of the Universal Mind (UM). This UM is constituted by these TCP and TRP which, in turn, are the ultimate constituents of any matter and any mind in the inherent presence of thought force (TF) in vitro and thought force (TF) in vivo. It is to be noted that these TCP and TRP are the ultimate constituents of any matter in the inherent presence of thought force (TF) in vitro. And these TCP and TRP are the ultimate constituents of any mind in the inherent presence of thought force (TF) in vivo. Pal et al $[1,3]$ explained that any matter as well as any individual mind is constituted by these TCP and TRP in the inherent presence of Thought force (TF) in vitro and Thought force (TF) in vivo.

Modern Scientists are not yet able to understand how the brain works to make the mind. They know that brain has got neurons that communicate across synapses by releasing a neurotransmitter, and that generates electrical impulses, and the receiving neuron then talks to its neighbor neurons the same way. If the mind depends on the brain, then all aspects of the mind are going to depend on these simple electrical, chemical processes. According to this concept, the existence of the UM requires the existence of the universal brain to form the UM. The concept of universal brain is not logically acceptable. Thus the concept that the mind depends on the brain becomes questionable if the existence of the UM is valid.

\subsection{Scientists would have to conclude clearly what is the Exact Definition of Mind}

It appears that scientists would have to decide in a purpose to conclude clearly whether mind is a 'state' (created by the activities of the brain with other parts of the nervous system as it is indicated by the functional view of mind) or 'a finer matter' (as it is indicated by the Indian Upanishads and Vedanta).

\subsection{Mind is a Finer Matter According to the Indian Upanishads and Vedanta}

It is our view that mind is a finer matter. The ultimate constituents of any mind are these TCP and TRP in the presence of thought force $\left(\mathrm{T}_{\mathrm{F}}\right)$ in vivo.

\subsection{What are the Ultimate Constituents of Any Matter?}

In our view, the ultimate constituents of any matter are these TCP and TRP in the presence of thought force $\left(\mathrm{T}_{\mathrm{F}}\right)$ in vitro.

\section{Special Characteristics of Mind and Consciousness}

(i) The basic mystery of the mind is how does it emerge from pure matter? How do those units that are made of tiny particles, give rise to the unique and essentially private, experience called consciousness? Do the particles that constitute our brain determine what we think and do? Do these tiny particles ultimately govern the thinking ability of the bioelectrical system? Or, are we free to have our own will? Is consciousness just froth sitting on top of the brain's electronics? How consciousness is being operated? Why should a bunch of atoms have thinking ability? Gross answers to all these inquiries are possible if we accept these TCP and TRP as the ultimate constituents of mind and matter in the inherent presence of thought force $\left(\mathrm{T}_{\mathrm{F}}\right)$ in vivo and thought force $\left(\mathrm{T}_{\mathrm{F}}\right)$ in vitro as indicated by $\mathrm{Pal}$ et al [3]. It is to be noted that the thought force $\left(\mathrm{T}_{\mathrm{F}}\right)$ being a primordial quantum field exerts its functions both in vitro and in vivo.

(ii) Modern Scientists are not yet able to understand how the brain works to make the mind. They know that brain has got neurons that communicate across synapses by releasing a neurotransmitter, and that generates electrical impulses, and the receiving neuron then talks to its neighbors the same way. If the mind depends on the brain, then all aspects of the mind are going to depend on these simple electrical, chemical processes. According to this concept, the existence of the UM requires the existence of the universal brain to form the UM. The concept of universal brain is not logically acceptable. Thus the concept that the mind depends on the brain becomes questionable if the existence of the $\mathrm{UM}$ is valid.

(iii) We are what our minds make us. The mind is a very powerful controller of the body. The mind controls everything as indicated by $\mathrm{Pal}$ et al [1,3] and Pal [7]. Mind is conditioned from the time we are young. It gives our abilities, our perceptions, our character and the way we think. From science to religion, from politics to economics, everything is controlled by the human mind. We perceive, we believe and we react. Things that matter are what we think they are. The quest for truth is bafflingly elusive, after all what is the 'truth'? We have come to the realization that if I believe it is true, it indeed is true for me, regardless of how incredible you may think it is. Experiments do not matter, arguments do not matter, reality does not matter, in fact, matter does not matter---it is all in the mind. As a joker succinctly put it, "It is a case of mind over matter-I do not mind and you do not matter".

(iv) Consciousness model of Pal et al [1-3] involving TCP, TRP and thought force $\left(\mathrm{T}_{\mathrm{F}}\right)$ signifies the existence of universal consciousness that exists along with the universe. Pal et al [3] showed that this universal consciousness is a functional state of Universal Mind (UM). Pal et al [3] explained that the UM is evolved at the Big Bang from the eternal Void. This Void, in turn, is the source of infinite energy. And this UM is a finer matter. The individual mind being a constituent of the $\mathrm{UM}$ is also a finer matter. The constituents of the UM and individual mind are the same. The ultimate 
constituents of matter and mind are the same as both mind and matter are aspects of one fundamental reality, which is called UM. The brain is the mediating link or interface between the individual mind and body. Pal et al [3] explained that the constituents of the UM are the ultimate constituents of matter itself as everything in this universe is a manifestation of this UM. Pal et al [3] expressed that the UM is constituted by these TCP and TRP in the inherent presence of thought force $\left(\mathrm{T}_{\mathrm{F}}\right)$. Pal et al [1, 3] further explained that the ultimate constituents of matter and mind are these TCP and TRP in the inherent presence of thought force $\left(\mathrm{T}_{\mathrm{F}}\right)$ in vitro and thought force $\left(\mathrm{T}_{\mathrm{F}}\right)$ in vivo.

(v) Current scientific views regarding the origin of consciousness vary widely and range from an 'epiphenomenon' arising from neuronal networks, to neuronal quantum processes, to a separate undiscovered scientific entity.

(vi) Consciousness is the functional state of mind. Presence of consciousness signifies the presence of mind and vice versa. It is to be understood that consciousness is the realization of existence and consciousness moves up and down on the 'scale of the realization' of existence through the 'sub-conscious', 'conscious' and 'superconscious' states as indicated by Pal et al [2].

(vii) Consciousness may be defined as the 'self-organized' capability of any living being to activate TCP and TRP, the ultimate constituents of mind and matter and to exert its functions. What can generate, maintain and activate TCP and TRP is called animate having 'active consciousness' and what cannot is called inanimate, i.e., devoid of active consciousness.

(viii) Continuity of consciousness is found through the experimental observations of Parnia[14], Lommel [15], Fenwick [16] and Beauregard \& O'Leary [17 \& 18] and demonstrate the existence of consciousness during the cessation of brain activity and thus support the existence of universal consciousness as well as substantial view of mind as indicated by the Indian Upanishads and Vedanta.

(ix) Everything in this universe is interlinked and intertwined through the existence of the quantum mechanical activities of these TCP in the inherent presence of TRP. Pal et al [1,3] showed that the quantized energy $\left(\varepsilon_{T}\right)$ of TCP is responsible to cause the universal consciousness as well as the cosmic microwave background radiation temperature. The individual consciousness owes its origin to the universal consciousness created by the same $\varepsilon_{T}$. Ultimately this $\mathcal{E}_{T}$ represents universal consciousness. This universal consciousness functions as a universe wide web (uww) covering the universe as a whole with all its parameters (including void) and inhabitants (with or without consciousness). In this picture, uww of consciousness, quantum concepts like wave particle dualism, position momentum uncertainty, nonlocality and concept of unified field become somewhat understandable as all the entities of this universe are interlinked and intertwined. In this picture, the universal consciousness replaces ether of yesteryears and contains the whole of the universe in its fold. The 'spooky action-at-adistance' may thus be built in nature through the existence of these TCP and TRP in the presence of thought force $\left(\mathrm{T}_{\mathrm{F}}\right)$.

(x) In a purpose to conclude clearly, it appears, that scientists would have to decide whether mind is a 'state' (created by the activities of the brain with other parts of the nervous system as it is indicated by the functional view of mind) or 'a finer matter' (as it is indicated by the Indian Upanishads and Vedanta).

\section{Plausible Drawbacks of the Functional View of Mind}

(i) The science of the mind may be connected with the science of the body. It is possible that the modern mind has been developed to get its present shape by the directive of the UM. The mind is an all-purpose computer responding impartially to the world around it; and this mind had, through natural selection, evolved to respond in a particular way to particular environmental circumstances. Humans are 'adaptation executors' carrying out programs written into the mind's machinery long ago. "The machinery does not know its own programming", said Cosmides and Tooby [19, 20, 21], intellectual leading evolutionary psychologists. The evolutionary psychologists see the mind as preprogrammed, made up of specialized mechanisms--'modules' or 'organs'. The evolutionary psychologists argue that their job is to approach the mind as an ancient engineering project, developing and testing out hypotheses about what 'designed problems' needed solving. Evolutionary psychologists thus signify the existence of the UM. Such an approach offers a badly needed bridge between psychology and the natural sciences. A plausible bridge between psychology and the natural sciences can be achieved through the developed consciousness model.

(ii) Growing evidence of the continuity of consciousness demonstrates the existence of consciousness during the cessation of brain activity. In a purpose to determine the nature of human mind and consciousness as well as its relationship with the brain, Parnia[14], Lommel [15], Fenwick [16] and Beauregard \& O'Leary [17 \& 18] observed through different lines of experiments and through studies of cardiac arrest survivors that the cerebral functioning as measured by electrical activity of the brain ceases during cardiac arrest. Sam Parnia [14] observed in the cardiac arrest survivors that the human mind and consciousness continue to function in the absence of brain function when there is cardiac arrest. Thus observations in these studies of cardiac arrest survivors raise the possibility that human mind and consciousness may continue to function in the 
absence of brain function. This indicates the existence of universal consciousness. The nervous system is evolved to individualize this universal consciousness that, in turn, exists along with the universe. These experimental observations support the substantial view of mind as indicated by the Indian Upanishads and Vedanta.

(iii) Continuity of consciousness indicates the existence of universal consciousness that exists along with the universe. This universal consciousness is to be taken into account, but usually ignored. Many physicists agree with the idea that consciousness is non-local, fundamental in the universe and consciousness is very much a part of the universe, like other objects. This universal consciousness is a functional state of the UM that, in turn, is a finer matter. Both, mind and matter are aspects of one fundamental and underlying reality, which is called Universal Mind (UM). The functional state of the UM is the universal consciousness that exists along with the universe. It appears that inanimate matter itself cannot generate consciousness without the inherent existence of this universal consciousness.

(iv) As per the ancient Vedanta, everything in this universe is a manifestation of the UM. This UM is a finer matter. The individual mind being a constituent of the UM is also a finer matter. The constituents of the UM and individual mind are the same. The ultimate constituents of matter and mind are the same as both mind and matter are aspects of one fundamental reality, which is called UM. The brain is the mediating link or interface between the individual mind and body.

(v) Pal et al [3] explained that the constituents of the UM are the ultimate constituents of matter itself as everything in this universe is a manifestation of this UM. Pal et al [3] expressed that the UM is constituted by these TCP and TRP in the inherent presence of thought force (TF). Pal et al $[1,3]$ further explained that the ultimate constituents of matter and mind are these TCP and TRP in the inherent presence of thought force (TF) in vitro and thought force (TF) in vivo.

(vi) According to the Vedanta, consciousness is not an emergent property of matter that comes into existence only through the functioning of the human nervous system. Instead, consciousness is a characteristic of reality, pervading all manifestations. This unbounded field of nature's universal consciousness is not limited to an individual consciousness. From this viewpoint, the role of the human nervous system is to provide an appropriate material structure to individualize this universal consciousness.

(vii) The human nervous system is evolved to provide an appropriate material structure to individualize the universal consciousness, which is a characteristic of reality, pervading all manifestations. This unbounded field of nature's 'universal consciousness' is not limited to an individual consciousness.

(viii) We are what our minds make us. The mind is a very powerful controller of the body. It appears that the mind controls everything. Mind exerts its role from the very beginning of life. It governs our abilities, our faculties, our perceptions, our attitudes, our character and the way we become habituated to think through the utilization of the instrumental brain.

(ix) Freeman J. Dyson said, "It appears that mind, as manifested by the capacity to make choices, is to some extent inherent in every atom".

(x) If mind has the capacity to make choices then this quality is demonstrated by atoms which make unpredictable choices between alternate possibilities according to the laws of quantum mechanics. "If the quality of mind is present at the atomic level, this suggests a return to the Vedantic concept of a Universal Mind (UM) which pervades all matter: a concept in agreement with the conclusion of University of Oregon physicist Amit Goswami. This UM must have been present at the inception of the universe".

(xi) Consciousness, not matter, is the ground of all existence, declares University of Oregon physicist Goswami, echoing the mystic sages of his native India. He holds that the universe is self-aware, and that consciousness creates the physical world. Matter is an expression of mind, not separate from mind, but mind manifested materially.

(xii) Example of three friends with different mental qualities. Let us take the popular example of a case of three friends visiting an ocean. If it is observed that one of them is frightened, other one is delighted and third person remains indifferent on the first sight of an ocean provided that they have not come in contact with the ocean before, then what should be the interpretation of mind that is related to the functions of the brain? These three different persons use their eyes and brains as the same type of instrument to look at the ocean. Here, the usual functioning of brain mechanism is not producing the same result on these three specified persons. The differences in the qualitative experiences are not due to the different functioning of the brain mechanism. The qualitative feelings are absolutely personal and mental. The brain is functioning as an instrument to generate different types of qualitative feelings in the different persons depending on their mental status. This mental status of a man is the result of the sum total of all the previous mental impressions (of previous lives) that he is not able to remember in this present life, because he has already lost all the previous brains. Further, this mental status is not the outcome of the activities of the brain with the other parts of the nervous system. The mind or the mental status does not depend on the activity of the brain. All our qualities are basically mental. If the brain is 
the cause and the mind is the effect, then who is controlling our mental qualities? The brain does not generate and control mental qualities. The brain is simply the biologically evolved fine instrument through which the mental impressions as well as mental qualities are expressed and maintained.

(xiii) We sometimes use the terms like 'beautiful mind' or 'vicious mind'. When we say that John Nash has a 'beautiful mind' (vide the cinema of same name), we do not simply mean that he has a beautiful brain only. On the contrary, we like to indicate that he has a special power within himself to utilize his brain for producing beautiful results for which we conclude that he has a 'beautiful mind'. In other words, the mental status or the inner mental power of John Nash enforces him to apply his brain in such a special way that the ultimate result is beautiful. The brain is nothing but a fine instrument through which the mind exerts its functions and the mind possesses the inner power (or mental qualities). When the mind desires to do something as per its mental impressions, it exerts its functions through the brain with other parts of the nervous system.

(xiv) Driving force of love and hate: We always find the action of 'driving forces' like "Attractive and Repulsive forces" which are the outcome of the emotional power of love, hate, fear and other emotional aspects of the mental world. Mind and consciousness generate and control all these driving forces. I would not like to go to a person whom I hate but I would be eager to go to a person whom I personally love. This emotional aspect of my mental world is controlling my physical movements through my nervous system. These vital interactions manifest their actions in the external physical world through the movements of the physical body. And these active interactions are controlling the physical movements of almost all the living beings, thus signifying the fact that the mind is a very powerful controller of the body.

(xv) Mind and mental qualities control the body through the utilization of the brain with other parts of the nervous system in the presence of sense organs. Strokes and fatal accidents sometimes cause complete paralysis but leave 'thought processes' of the victims untouched, trapping the 'active mind' in a motionless body. It indicates that the brain is functioning as the inter-linking device between the body and mind. It is also to be noted that human beings in 'coma' state do not exhibit significant consciousness in the presence of 'life function'. This is due to the malfunction of the brain that is the proper instrument through which the mind exerts its functions with the help of TCP and TRP. These TCP and TRP are ultimately responsible to generate consciousness and awareness. Pal et al [3] expressed that the quantized energy $\left(\mathcal{E}_{T}\right)$ of the TCP represents consciousness.

(xvi) Soul (Void) exerts its functions through the finer instrument called mind. This mind, in turn, exerts its functions through the brain with other parts of nervous system (CNS, PNS along with ANS).

(xvii) The eternal Void has been covered by the mind to function as the Soul of the individual being. In the

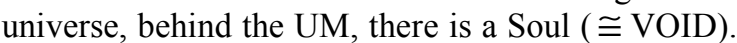
In the individual, behind the individual mind (which is a constituent of the UM), there is also a Soul ( $\cong$ VOID). Any matter as well as any individual mind is constituted by these TCP and TRP that, in turn, are originated from the same eternal Void. Thus the individual mind is operated by these TCP and TRP that, in turn, are ultimately governed and operated by the same eternal Void. The individual mind being a constituent of the UM has covered the eternal Void to serve the role of individual 'Soul'. This eternal Void is thus the common source and the source is still with us. This Void serves the role of Soul being covered by the mind. The mind-brain and brain-body links which are addressed by psychology, cognitive science, neuroscience and neurophysiology are, in our proposition, ultimately governed by the quantum mechanical activities of these TCP and TRP in the inherent presence of thought force (TF) in vitro and thought force (TF) in vivo. Consciousness that signifies the realization of existence is a functional state of mind.

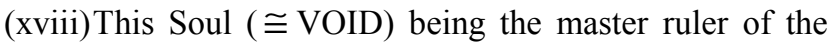
body exerts its functions through the finer instrument called mind. This mind (with the help of TCP and TRP), in turn, exerts its functions through the brain with other parts of nervous system (CNS, PNS along with ANS) in the biological systems in order to grasp this physical universe, of course, in the inherent presence of consciousness. This consciousness is created and maintained by the quantum mechanical activities of these TCP in the inherent presence of TRP. Thus any matter (as well as mind) being ultimately composed of these TCP and TRP should have some sort of 'mind' as Dyson indicated. The more the development of the organized brain, the more the degree of manifestation of consciousness indicated by $\mathrm{Pal}$ et al [2]. This consciousness itself is acting as an interlinking agent between the animate and inanimate through the quantum mechanical activities of these TCP in the presence of TRP. Thus these TCP and TRP being the ultimate constituents of mind as well as matter play the most significant roles in many present day scientific enigmas.

(xix) Consciousness in living organisms is a process which involves the quantum mechanical activities of these TCP and TRP, the ultimate constituents of matter and mind in the inherent presence of thought force (TF) in vitro and thought force (TF) in vivo as indicated by Pal et al [1-3]. And these TCP and TRP govern the activities of neurons (not the other way round). These neurons are simply the equipments used to generate consciousness and awareness. The 
consciousness itself is functioning as an interlinking agent between the animate and inanimate.

(xx) The quantum mechanical activities of these TCP and TRP could also explain self-organization.

(xxi) Josephson et al [22] explained that both psychokinesis and telepathy might be found in quantum physics. It is our view that both psychokinesis and telepathy can be thoroughly interpreted through the consciousness model involving the quantum mechanical activities of TCP and TRP in the inherent presence of thought force (TF) in vitro and the thought force (TF) in vivo.

(xxii) It appears that the development of 'selforganization' is possible through the generation and maintenance of consciousness by the quantum mechanical activities of these TCP and TRP, the ultimate constituents of matter and mind in the inherent presence of thought force (TF) in vitro and thought force (TF) in vivo.

(xxiii)Conclusion of Parnia [14] is human consciousness may work independently of the brain. Just because the brain is damaged does not necessarily mean that the "mind" is affected. This observation indicates that consciousness owes its origin to the universal consciousness. This consciousness, in turn, exists along with the universe; and thus consciousness is independent of the brain. Damaged brain does not necessarily mean that the "mind" is affected, thereby, signifies the substantial view of mind but not the functional view of mind.

(xxiv) The notions of a person's "spirit" and "soul" often overlap, as both contrast with body and both are imagined as surviving the bodily death in religion and occultism, and "spirit" can also have the sense of "ghost" (such as demons or deities) i.e. manifestations of the spirit of a deceased person. Barking of a pet dog looking at the window in a purpose to threaten and drive out 'something unwanted' appears to indicate the probable presence of something or someone that is nothing but a 'spirit' which is a spiritual body or mental body [called Linga Sharira or Sukshma Sharira in Sanskrit] indicated by Vivekananda [13]. Usually the human eye cannot recognize this spirit or mental body, but dogs and cats can do so. Functional view of mind cannot explain the possible existence of a spirit or a mental body.

\section{The Power of the Mind as Expressed by Swami Vivekananda [23]:}

(Swami Vivekananda [23] had delivered this lecture at Los Angeles, California, on January 8, 1900 as mentioned in "The complete works of Swami Vivekananda").

About the power of the mind I like to point out what Swami Vivekananda [23] had to say:

All over the world there has been the belief in the supernatural throughout the ages. All of us have heard of extraordinary happenings, and many of us have had some personal experience of them. I would rather introduce the subject by telling you certain facts which have come within my own experience. I once heard of a man who, if any one went to him with questions in his mind, would answer them immediately; and I was also informed that he foretold events. I was curious and went to see him with a few friends. We each had something in our minds to ask, and, to avoid mistakes, we wrote down our questions and put them in our pockets. As soon as the man saw one of us, he repeated our questions and gave the answers to them. Then he wrote something on paper, which he folded up, asked me to sign on the back, and said, "Don't look at it; put it in your pocket and keep it there till I ask for it again." And so on to each one of us. He next told us about some events that would happen to us in the future. Then he said, "Now, think of a word or a sentence, from any language you like." I thought of a long sentence from Sanskrit, a language of which he was entirely ignorant. "Now, take out the paper from your pocket," he said. The Sanskrit sentence was written there! He had written it an hour before with the remark, "In confirmation of what I have written, this man will think of this sentence." It was correct. Another of us who had been given a similar paper which he had signed and placed in his pocket, was also asked to think of a sentence. He thought of a sentence in Arabic, which it was still less possible for the man to know; it was some passage from the Koran. And my friend found this written down on the paper. Another of us was a physician. He thought of a sentence from a German medical book. It was written on his paper.

Several days later I went to this man again, thinking possibly I had been deluded somehow before. I took other friends, and on this occasion also he came out wonderfully triumphant.....

Swami Vivekananda [23] continued----- I saw many things like that. Going about India you find hundreds of similar things in different places. These are in every country. Even in this country you will find some such wonderful things. Of course there is a great deal of fraud, no doubt; but then, whenever you see fraud, you have also to say that fraud is an imitation. There must be some truth somewhere, that is being imitated; you cannot imitate nothing. Imitation must be of something substantially true.

In very remote times in India, thousands of years ago, these facts used to happen even more than they do today. It seems to me that when a country becomes very thickly populated, psychical power deteriorates. Given a vast country thinly inhabited, there will, perhaps, be more of psychical power there. These facts, the Hindus, being analytically minded, took up and investigated. And they came to certain remarkable conclusions; that is, they made a science of it. They found out that all these, though extraordinary, are also natural; there is nothing supernatural. They are under laws just the same as any other physical phenomenon. It is not a freak of nature that a man is born with such powers. They can be systematically studied, practiced, and acquired. This science they call the science of Râja-Yoga. There are 
thousands of people who cultivate the study of this science, and for the whole nation it has become a part of daily worship.

The conclusion they have reached is that all these extraordinary powers are in the mind of man. This mind is a part of the universal mind. Each mind is connected with every other mind. And each mind, wherever it is located, is in actual communication with the whole world [due to the existence of universal consciousness that is a functional state of the universal mind. It has already been expressed that consciousness model of Pal et al [1-3] involving TCP, TRP and thought force $\left(T_{F}\right)$ signifies the existence of universal consciousness that exists along with the universe. Pal et al [3] showed that this universal consciousness is a functional state of Universal Mind (UM). Pal et al [3] explained that the UM is evolved at the Big Bang from the eternal Void. This Void, in turn, is the source of infinite energy. And this UM is a finer matter. The individual mind being a constituent of the UM is also a finer matter. The constituents of the UM and individual mind are the same. The ultimate constituents of matter and mind are the same as both mind and matter are aspects of one fundamental reality, which is called UM. The brain is the mediating link or interface between the individual mind and body.

Pal et al [3] explained that the constituents of the UM are the ultimate constituents of matter itself as everything in this universe is a manifestation of this UM. Pal et al [3] expressed that the UM is constituted by these TCP and TRP in the inherent presence of thought force $\left(T_{F}\right)$. Pal et al [1, 3] further explained that the ultimate constituents of matter and mind are these TCP and TRP in the inherent presence of thought force $\left(T_{F}\right)$ in vitro and thought force $\left(T_{F}\right)$ in vivo.] NOTE: Italics are added by the author for further clarifications.

Swami Vivekananda [23] continued...

Have you ever noticed the phenomenon that is called thought-transference? A man here is thinking something, and that thought is manifested in somebody else, in some other place. With preparations - not by chance - a man wants to send a thought to another mind at a distance, and this other mind knows that a thought is coming, and he receives it exactly as it is sent out. Distance makes no difference. The thought goes and reaches the other man, and he understands it. If your mind were an isolated something here, and my mind were an isolated something there, and there were no connection between the two, how would it be possible for my thought to reach you? In the ordinary cases, it is not my thought that is reaching you direct; but my thought has got to be dissolved into ethereal vibrations (this is nothing but the universal consciousness that functions as a universe wide web (uww) covering the universe as a whole... the universal consciousness replaces ether of yesteryears and contains the whole of the universe in its fold) and those ethereal vibrations go into your brain, and they have to be resolved again into your own thoughts. Here is dissolution of thought, and there is a resolution of thought. It is a roundabout process. But in telepathy, there is no such thing; it is direct. [Pal [24] showed that 'Thought' is a kind of force being carried by the TCP. A TCP has the capacity to carry a specific 'thought'. This TCP is converted into a TRP in the presence of consciousness to retain and store a specific 'thought' (or 'idea') as both these TCP and TRP are interchangeable in the presence of consciousness. Thus, in the presence of consciousness, these TCP and TRP are inter-convertible to carry and retain a specific "thought" and also for its communication from one person to another in the presence of the thought force $\left(T_{F}\right)$ in vitro and thought force $\left(T_{F}\right)$ in vivo]. NOTE: Italics are added by the author for further clarifications.

This shows that there is a continuity of mind (due to the existence of the universal consciousness that functions as a universe wide web (uww) covering the universe as a whole), as the Yogis call it. The mind is universal. Your mind, my mind, all these little minds, are fragments of that universal mind, little waves in the ocean; and on account of this continuity, we can convey our thoughts directly to one another.

You see what is happening all around us. The world is one of influence. Part of our energy is used up in the preservation of our own bodies. Beyond that, every particle of our energy is day and night being used in influencing others. Our bodies, our virtues, our intellect, and our spirituality, all these are continuously influencing others; and so, conversely, we are being influenced by them. This is going on all around us. Now, let us take a concrete example. A man comes; you know he is very learned, his language is beautiful, and he speaks to you by the hour; but he does not make any impression. Another man comes, and he speaks a few words, not well arranged, ungrammatical perhaps; all the same, he makes an immense impression. Many of you have seen that. So it is evident that words alone cannot always produce an impression. Words, even thoughts contribute only one-third of the influence in making an impression, the man, two-thirds. What you call the personal magnetism of the man - that is what goes out and impresses you.

In our families there are the heads; some of them are successful, others are not. Why? We complain of others in our failures. The moment I am unsuccessful, I say, so-and-so is the cause of the failure. In failure, one does not like to confess one's own faults and weaknesses. Each person tries to hold himself faultless and lay the blame upon somebody or something else, or even on bad luck. When heads of families fail, they should ask themselves, why it is that some persons manage a family so well and others do not. Then you will find that the difference is owing to the man - his presence, his personality.

Coming to great leaders of mankind, we always find that it was the personality of the man that counted. Now, take all the great authors of the past, the great thinkers. Really speaking, how many thoughts have they thought? Take all the writings that have been left to us by the past leaders of mankind; take each one of their books and appraise them. The real thoughts, new and genuine, that have been thought in this world up to this time, amount to only a handful. Read in their books the 
thoughts they have left to us. The authors do not appear to be giants to us, and yet we know that they were great giants in their days. What made them so? Not simply the thoughts they thought, neither the books they wrote, nor the speeches they made, it was something else that is now gone, that is their personality. As I have already remarked, the personality of the man is two-thirds, and his intellect, his words, are but one-third. It is the real man, the personality of the man, that (is to be taken into account) runs through us. Our actions are but effects. Actions must come when the man is there; the effect is bound to follow the cause.

The ideal of all education, all training, should be this manmaking. But, instead of that, we are always trying to polish up the outside. What use in polishing up the outside when there is no inside? The end and aim of all training is to make the man grow. The man who influences, who throws his magic, as it were, upon his fellow-beings, is a dynamo of power, and when that man is ready, he can do anything and everything he likes; that personality put upon anything will make it work.

Now, we see that though this is a fact, no physical laws that we know of will explain this. How can we explain it by chemical and physical knowledge? How much of oxygen, hydrogen, carbon, how many molecules in different positions, and how many cells, etc., etc. can explain this mysterious personality? And we still see, it is a fact, and not only that, it is the real man; and it is that man that lives and moves and works, it is that man that influences, moves his fellow-beings, and passes out, and his intellect and books and works are but traces left behind. Think of this. Compare the great teachers of religion with the great philosophers. The philosophers scarcely influenced anybody's inner man, and yet they wrote most marvellous books. The religious teachers, on the other hand, moved countries in their lifetime. The difference was made by personality. In the philosopher it is a faint personality that influences; in the great prophets it is tremendous. In the former we touch the intellect, in the latter we touch life. In the one case, it is simply a chemical process, putting certain chemical ingredients together which may gradually combine and under proper circumstances bring out a flash of light or may fail. In the other, it is like a torch that goes round quickly, lighting others.

The science of Yoga claims that it has discovered the laws which develop this personality, and by proper attention to those laws and methods, each one can grow and strengthen his personality. This is one of the great practical things, and this is the secret of all education. This has a universal application...... Let us say, it is a sort of tapering existence; the thickest part is here, it tapers and becomes finer and finer. The finest is what we call spirit; the grossest, the body. And just as it is here in microcosm, it is exactly the same in the macrocosm. The universe of ours is exactly like that; it is the gross external thickness, and it tapers into something finer and finer until it becomes God.

We also know that the greatest power is lodged in the fine, not in the coarse. We see a man take up a huge weight, we see his muscles swell, and all over his body we see signs of exertion, and we think the muscles are powerful things. But it is the thin thread-like things, the nerves, which bring power to the muscles; the moment one of these threads is cut off from reaching the muscles, they are not able to work at all. These tiny nerves bring the power from something still finer, and that again in its turn brings it from something finer still - thought, and so on. So, it is the fine that is really the seat of power. Of course we can see the movements in the gross; but when fine movements take place, we cannot see them. When a gross thing moves, we catch it, and thus we naturally identify movement with things which are gross. But all the power is really in the fine. We do not see any movement in the fine, perhaps, because the movement is so intense that we cannot perceive it. But if by any science, any investigation, we are helped to get hold of these finer forces which are the cause of the (external) expression, the expression itself will be under control. There is a little bubble coming from the bottom of a lake; we do not see it coming all the time, we see it only when it bursts on the surface; so, we can perceive thoughts only after they develop a great deal, or after they become actions. We constantly complain that we have no control over our actions, over our thoughts. But how can we have it? If we can get control over the fine movements, if we can get hold of thought at the root, before it has become thought, before it has become action, then it would be possible for us to control the whole. Now, if there is a method by which we can analyze, investigate, understand, and finally grapple with those finer powers, the finer causes, then alone is it possible to have control over ourselves, and the man who has control over his own mind assuredly will have control over every other mind. That is why purity and morality have been always the object of religion; a pure, moral man has control of himself. And all minds are the same, different parts of one Mind (i.e. Universal Mind). He who knows one lump of clay has known all the clay in the universe. He who knows and controls his own mind knows the secret of every mind and has power over every mind.

Swami Vivekananda [23] continued----Now, a good deal of our physical evil we can get rid of, if we have control over the fine parts; a good many worries we can throw off, if we have control over the fine movements; a good many failures can be averted, if we have control over these fine powers. So far, is utility. Yet beyond, there is something higher.

Each man in his childhood runs through the stages through which his race has come up; only the race took thousands of years to do it, while the child takes a few years. The child is first the old savage man - and he crushes a butterfly under his feet. The child is at first like the primitive ancestors of his race. As he grows, he passes through different stages until he reaches the development of his race. Only he does it swiftly and quickly. Now, take the whole of humanity as a race, or take the whole of the animal creation, man and the lower animals, as one whole. There is an end towards which the whole is moving. Let us call it perfection. Some men and women are born who anticipate the whole progress of mankind. Instead of waiting and being reborn over and over again for ages until the whole human race has attained to that 
perfection, they, as it were, rush through them in a few short years of their life. And we know that we can hasten these processes, if we be true to ourselves. If a number of men, without any culture, be left to live upon an island, and are given barely enough food, clothing, and shelter, they will gradually go on and on, evolving higher and higher stages of civilization. We know also, that this growth can be hastened by additional means. We help the growth of trees, do we not? Left to nature they would have grown, only they would have taken a longer time; we help them to grow in a shorter time than they would otherwise have taken. We are doing all the time the same thing, hastening the growth of things by artificial means. Why cannot we hasten the growth of man? We can do that as a race. Why are teachers sent to other countries? Because by these means we can hasten the growth of races. Now, can we not hasten the growth of individuals? We can. Can we put a limit to the hastening? We cannot say how much a man can grow in one life. You have no reason to say that this much a man can do and no more. Circumstances can hasten him wonderfully. Can there be any limit then, till you come to perfection?

The Yogis say that all great incarnations and prophets are such men; that they reached perfection in this one life. We have had such men at all periods of the world's history and at all times.

Even this hastening of the growth must be under laws. Suppose we can investigate these laws and understand their secrets and apply them to our own needs; it follows that we grow. We hasten our growth, we hasten our development, and we become perfect, even in this life. This is the higher part of our life, and the science of the study of mind and its powers has this perfection as its real end. Helping others with money and other material things and teaching them how to go on smoothly in their daily life are mere details.

The utility of this science is to bring out the perfect man, and not let him wait and wait for ages, just a plaything in the hands of the physical world, like a log of drift-wood carried from wave to wave and tossing about in the ocean. This science wants you to be strong, to take the work in your own hand, instead of leaving it in the hands of nature, and get beyond this little life. That is the great idea.

Man is growing in knowledge, in power, in happiness. Continuously, we are growing as a race. We see that is true, perfectly true. Is it true of individuals? Yes, to a certain extent. But yet, again there is the question: Where do you fix the limit? I can see only at a distance of so many feet. But I have seen a man close his eyes and see what is happening in another room. If you say you do not believe it, perhaps in three weeks that man can make you do the same. It can be taught to anybody. Some persons, in five minutes even, can be made to read what is happening in another man's mind. These facts can be demonstrated.

Now, if these things are true, where can we put a limit? If a man can read what is happening in another's mind in the corner of this room, why not in the next room? Why not anywhere? We cannot say, why not. We dare not say that it is not possible. We can only say, we do not know how it happens. Material scientists have no right to say that things like this are not possible; they can only say, "We do not know." Science has to collect facts, generalize upon them, deduce principles, and state the truth - that is all. But if we begin by denying the facts, how can a science be?

There is no end to the power a man can obtain. This is the peculiarity of the Indian mind, that when anything interests it, it gets absorbed in it and other things are neglected. You know how many sciences had their origin in India. Mathematics began there. You are even today counting 1, 2, 3, etc. to zero (this zero is the invention of India), after Sanskrit figures. And gravitation was known to the Indians thousands of years before Newton was born.

At a certain period of Indian history, this one subject of man and his mind absorbed all their interest. And it was so enticing, because it seemed the easiest way to achieve their ends. Now, the Indian mind became so thoroughly persuaded that the mind could do anything and everything according to law, that its powers became the great object of study. Charms, magic, and other powers, and all that were nothing extraordinary, but a regularly taught science, just as the physical sciences they had taught before that. Such a conviction in these things came upon the race that physical sciences nearly died out. It was the one thing that came before them. Different sects of Yogis began to make all sorts of experiments. Some made experiments with light, trying to find out how lights of different colours produced changes in the body. They wore a certain coloured cloth, lived under a certain colour, and ate certain coloured foods. All sorts of experiments were made in this way. Others made experiments in sound by stopping and unstopping their ears. And still others experimented in the sense of smell, and so on.

The whole idea was to get at the basis, to reach the fine parts of the thing. And some of them really showed most marvellous powers. Many of them were trying to float in the air or pass through it. I shall tell you a story which I heard from a great scholar in the West. It was told him by a Governor of Ceylon who saw the performance. A girl was brought forward and seated cross-legged upon a stool made of sticks crossed. After she had been seated for a time, the show-man began to take out, one after another, these crossbars; and when all were taken out, the girl was left floating in the air. The Governor thought there was some trick, so he drew his sword and violently passed it under the girl; nothing was there. Now, what was this? It was not magic or something extraordinary. That is the peculiarity. No one in India would tell you that things like this do not exist. The power is all in the spirit.

If this is true, it is temptation enough for the mind to exert its highest. But as with every other science it is very difficult to make any great achievement, so also with this, nay much more. Yet most people think that these powers can be easily gained. How many are the years you take to make a fortune? Think of that! First, how many years do you take to learn electrical science or engineering? And then you have to work all the rest of your life.

Again, most of the other sciences deal with things that are 
fixed. You can analyze the chair, the chair does not fly from you. But this science deals with the mind, which moves all the time; the moment you want to study it, it slips. Now the mind is in one mood, the next moment, perhaps, it is different, changing, changing all the time. In the midst of all this change it has to be studied, understood, grasped, and controlled. How much more difficult, then, is this science! It requires rigorous training. People ask me why I do not give them practical lessons. Why, it is no joke. I stand upon this platform talking to you and you go home and find no benefit; nor do I. Then you say, "It is all bosh." It is because you wanted to make bosh of it. I know very little of this science, but the little that I gained I worked for thirty years of my life, and for six years I have been telling people the little that I know. It took me thirty years to learn it; thirty years of hard struggle. Sometimes I worked at it twenty hours during the twenty-four; sometimes I slept only one hour in the night; sometimes I worked whole nights; sometimes I lived in places where there was hardly a sound, hardly a breath; sometimes I had to live in caves. Think of that. And yet I know little or nothing; I have barely touched the hem of the garment of this science. But I can understand that it is true and vast and wonderful.

Now, if there is any one amongst you who really wants to study this science, he will have to start with that sort of determination, the same as, nay even more than, that which he puts into any business of life.

And what an amount of attention does business require, and what a rigorous taskmaster it is! Even if the father, the mother, the wife, or the child dies, business cannot stop! Even if the heart is breaking, we still have to go to our place of business, when every hour of work is a pang. That is business, and we think that it is just, that it is right.

This science calls for more application than any business can ever require. Many men can succeed in business; very few in this. As in business all may not make a fortune, but everyone can make something, so in the study of this science each one can get a glimpse which will convince him of its truth and of the fact that there have been men who realized it fully.

Swami Vivekananda [23] concluded, "This is the outline of the science. It stands upon its own feet and in its own light, and challenges comparison with any other science. There have been charlatans, there have been magicians, there have been cheats, and more here than in any other field. Why? For the same reason, that the more profitable the business, the greater the number of charlatans and cheats. But that is no reason why the business should not be good. And one thing more; it may be good intellectual gymnastics to listen to all the arguments and an intellectual satisfaction to hear of wonderful things. But, if any one of you really wants to learn something beyond that, merely attending lectures will not do. That cannot be taught in lectures, for it is life; and life can only convey life. If there are any amongst you who are really determined to learn it, I shall be very glad to help them".

It is thus clear through the lectures of Swami Vivekananda [23] that there is the existence of the genuine power of the mind to influence other minds by the will-force in the presence of consciousness.

\subsection{The Importance of Psychology: "Psychology is the Science of Sciences" as Explained by Swami Vivekananda [25]}

Dash et al [26] mentioned an article entitled, "The Importance of Psychology" as expressed by Swami Vivekananda [25] more than a century ago:

"The idea of psychology in the West is very much degraded. Psychology is the science of sciences; but in the West, it is placed upon the same plane as all other sciences; that is, it is judged by the same criterion- utility. How much practical benefit will it do to humanity? How much will it add to our rapidly growing happiness? How much will it detract from our rapidly increasing pain? Such is the criterion by which everything is judged in the West.

People seem to forget that about ninety percent of all our knowledge cannot, in the very nature of things, be applied in a practical way to aid to our material happiness or to lessen our misery. Only the smallest fraction of our scientific knowledge can have any such application to our daily lives. This is so because only an infinitely small percentage of our conscious mind is on a sensuous plane. We have just a little bit of sensuous consciousness and imagine that to be our entire mind and life; but, as a matter of fact, it is but a drop in the mighty ocean of subconscious mind. If all there is of us were a bundle of sense-perceptions, all the knowledge we could gain could be utilized in the gratification of our sensepleasures. But unfortunately such is not the case. As we get further and further away from the animal state, our sensepleasures become less and less; and our enjoyment, in a rapidly increasing consciousness of scientific and psychological knowledge, becomes more and more intense; and "knowledge for the sake of knowledge", regardless of the amount of sense-pleasures it may conduce to, becomes the supreme pleasure of the mind.

But even taking the Western idea of utility as a criterion by which to judge, psychology, by such standard even, is the science of sciences. Why? We are all slaves to our senses, slaves to our own minds, conscious and subconscious. The reason why a criminal is a criminal is not because he desires to be one, but because he has not his mind under control and is therefore a slave to his own conscious and subconscious mind and to the mind of everybody else.

Deep down in our subconscious mind are stored up all the thoughts and acts of the past, not only of this life, but of all other lives we have lived. This great boundless ocean of subjective mind is full of all the thoughts and actions of the past. ...

It the science of psychology that teaches us to hold in check the wild gyrations of the mind, place it under the control of the will, and thus free ourselves from its tyrannous mandates. Psychology is therefore science of sciences, without which all sciences and all other knowledge are worthless.

The mind uncontrolled and unguided will drag us down, 
down, for ever- rend us, kill us; and the mind controlled and guided will save us, free us. So it must be controlled, and psychology teaches us how to do it.

\section{The Relationship between Consciousness and Vital Living Force

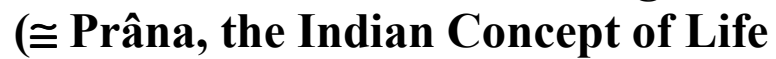 Energies)}

Fritjof Capra [27] expressed, "Both kinds of interconnectedness---that between mind and body and that between organism and environment---would have to be interpreted in terms of tentative notions of energy patterns. The Indian concept of 'Prâna' and the Chinese concept of ch'i are to be taken into account as examples of traditional terms referring to these 'subtle energies', or 'life energies'. In these traditional disciplines illness is seen as resulting from changes in the patterns of energy and therapeutic techniques have been developed to influence the body's energy system".

According to the ancient Indian Vedanta, this Universe is composed of 'Âkâsha' and 'Prâna' as indicated by Vivekananda [28]. 'Âkâsha' is the origin of all the observable matter. And 'Prâna' is the origin of all the natural fields along with vibrations (Thought). This natural field includes the 'vital living force' which, in turn, controls all the psychological as well as the physiological functions of all living beings of the universe. It is to be noted that this Prâna $\cong$ the Indian concept of 'life energies'. And this vital living force as well as the thought force is usually ignored.

It is to be noted that Prâna ( $\cong$ 'vital living force') $\cong$ thought force $\left(\mathrm{T}_{\mathrm{F}}\right)$ in vitro + thought force $\left(\mathrm{T}_{\mathrm{F}}\right)$ in vivo $+\mathrm{T}_{\mathrm{F}}$ (micro) $+\mathrm{T}_{\mathrm{F}}$ (macro).

Pal [5] explained vividly the existence of thought force $\left(\mathrm{T}_{\mathrm{F}}\right)$ in vitro and thought force $\left(\mathrm{T}_{\mathrm{F}}\right)$ in vivo and other characteristics of the thought force $\left(\mathrm{T}_{\mathrm{F}}\right)$.

Is the physical body of a living being cause of manifestation of the Soul ( $\cong$ Void) or 'vital living force' (called Prâna, the Indian concept of 'life energies')? What makes this body? What force causes the atoms to combine in a specific sequence and takes up specific atoms from the mass of matter around us in order to provide different shapes of different species of specific bodies of living beings? It is logical to say that the force which makes up the matter and forms the body, is the same force which is responsible for causing and maintaining the psychological as well physiological functions of the living organisms. This specific force is called "Prâna", the Indian concept of 'life energies'. The sum-total of the energy displayed in the universe is called Prâna indicated by Vivekananda [28]. This Prâna is thought to be the 'universal power'. The Prâna is the gross origin of all the fundamental fields including the 'vital living force' which controls all the psychological as well as the physiological functions of all living beings of the universe. TCP is the force-carrying particle of the original thought force $\left(T_{F}\right)$ which is the origin of all the existing natural fields. Thus, this "Prâna" is more or less equivalent to the original thought force $\left(\mathrm{T}_{\mathrm{F}}\right)$ which is carried by TCP in the inherent presence of TRP. Does this Prâna generate consciousness? Or does the consciousness create Prâna? Are they interdependent or intra-dependent? It is apparent that the consciousness being a typical form of energy can initiate the function of Prâna. Life may be defined as a state of functional manifestation of consciousness that, in turn, is the quantized energy ( $\varepsilon_{T}$ ) of the TCP. This $\varepsilon_{T}$ represents consciousness.

As a separate entity, the Prâna as well as consciousness appears to be independent or they may appear to be interdependent; but, after the initiation of the function of Prâna in a living organism, they are intra-dependent. Thus, when this specific 'vital living force' (i.e. Prâna ) is eliminated from the living organism, then that living being is said to die.

Pal [5] expressed that the thought force $\left(\mathrm{T}_{\mathrm{F}}\right)$ being the primordial quantum field functions as the original single primary unified field that is not only the origin of all the four fundamental fields along with both the $T_{F}$ (micro) and $T_{F}$ (macro) but also the origin of thought force $\left(\mathrm{T}_{\mathrm{F}}\right)$ in vivo.

Thus, the original thought force $\left(\mathrm{T}_{\mathrm{F}}\right)$ which is the primordial quantum field and which is an expression of the universal consciousness represents 'Prâna' that, in turn, is the origin of all the natural fields (including the vital living force) and TRP represents 'Âkâsha'. This 'Prâna' is manifested as nerve-current as well as the biological 'thought force' also. And all the psychological and physiological activities are controlled and maintained by this same 'Prâna' itself.

\subsection{What is "Prâna"?}

The "Prâna" is the grosser form of the original thought force $\left(\mathrm{T}_{\mathrm{F}}\right)$; its energy should be the quantized energy ( $\left.\mathcal{E}_{T}\right)$ of the TCP as it is expressed by Pal $[5,29]$ through the evolution of universe from the void:

$$
\text { Void } \rightarrow \mathrm{E}_{\mathrm{T}}=\varepsilon_{T}=\mathrm{m}_{\mathrm{T}} \mathrm{c}^{2}=\mathrm{hv}_{\mathrm{T}}=\mathrm{hc} / \lambda_{\mathrm{T}}=4.95 \times 10^{-16} \mathrm{erg}
$$

where, $\mathrm{E}_{\mathrm{T}}=$ total energy of the universe,

$\mathcal{E}_{T}=$ quantized energy of the TCP $=4.95 \times 10^{-16} \mathrm{erg}$

$\mathrm{m}_{\mathrm{T}}=$ quantized mass of the $\mathrm{TCP}=\varepsilon_{T} / \mathrm{c}^{2}=5.5 \times 10^{-37} \mathrm{~g}$,

$\mathrm{h}=$ Planck's quantum constant $=6.63 \times 10^{-27} \mathrm{erg} . \mathrm{sec}$,

$v_{\mathrm{T}}=$ frequency of the TCP $=7.466 \times 10^{10} \mathrm{cps}$,

$\lambda_{\mathrm{T}}=$ wavelength of the TCP radiated by the radiant mass of the universe $=\mathrm{hc} / \mathcal{E}_{T}=0.4018 \mathrm{~cm}$.

\section{Interpretation of the Indian Concept of MANTRAS-JAPA through the Quantum Mechanical Activities of these TCP and TRP as Explained by Pal [30]}

Pal [30] has shown that the 'MANTRA' is the vehicle through which one can arrive at the 'super-conscious' state 
via consciousness. Any pronounced word or 'vibration' can function as a 'MANTRA' provided it should have the vibrant power to cause sufficient vibration in the mind. When a Yogi (meditator) wants to recognize his own divine immortal existence through the vigorous concentration of his mind in order to find out the origin of the mind, then he will have to abolish or deactivate the activity of the elements (i.e. TCP and TRP) of the mind. This can be done only by elevating the conscious mind to its super-conscious state in a purpose to

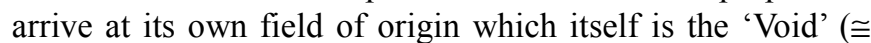

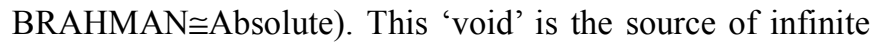
energy.

The power of the 'MANTRA' depends on the power to dissociate the mind in order to arrive at the origin of the mind through the release of the TCP and TRP from their bound state called mind. Thus the pronounced words that have this capability are regarded as 'MANTRAS'. Although any word can serve the function of 'MANTRA', yet there are certain proved specific words that are utilized as 'MANTRAS' for several thousand years.

'RAMA' is a word as well as a 'MANTRA'. If the word 'RAMA' cannot stimulate any vibration in my mind, then it is not a 'MANTRA' to me at all - it is just like other ordinary words in the normal sense. The inherent power of 'MANTRA' of the word 'RAMA" is dependent on the degree up to which extent it can generate vibration in the mind; and it would function as a 'MANTRA' only to that extent or intensity.

There should be a connection between the inanimate word and mind; and these two should positively come in contact with the 'consciousness' if the word itself is to function as a 'MANTRA'. Thus 'MANTRA-JAPA' is the effort to direct the combined word-mind complex towards the universal consciousness through the vehicle of individual consciousness. JAPA is the repeated recitation of the 'MANTRA' with honest faith and respect.

It is to be noted that the "PRANABA" / 'ONKAR' (OM) itself is the so-called "NADA BRAMHAN". Any pronounced 'word' has its origin to the 'PRANABA' / 'ONKAR' (OM) [i.e. "NADA BRAMHAN"]. And every pronounced 'word' ends in the vibration of 'PRANABA' / 'ONKAR' (OM). The 'PRANABA'/ 'ONKAR' (OM) is a word as well as a 'MANTRA'.The OM, mind and the effort to arrive at the field of consciousness should vibrate in a line so that there should be a resonance. It appears that UTF (universal thought frequency) $\cong$ frequency of the $\mathrm{TCP} \cong$ frequency of the "Prâna" $=7.466 \times 10^{10} \mathrm{cps} \cong$ frequency of ONKAR $(\mathrm{OM})$.

As the "Prâna" is the grosser form of the original thought force $\left(\mathrm{T}_{\mathrm{F}}\right)$, so it is apparent that the frequency of the TCP $\cong$ frequency of the "Prâna" $=7.466 \times 10^{10} \mathrm{cps} \cong$ frequency of ONKAR (OM).

It is to be understood that the "PRANABA" itself is the socalled "NADA BRAMHAN". It is apparent that the original frequency of ONKAR (OM) should have the same universal thought frequency (UTF) that, in turn, is the same frequency of TCP itself that is found to be $7.466 \times 10^{10} \mathrm{cps}$. When the frequency of pronounced "OM" attains its original frequency that, in turn, is the frequency of TCP (or the frequency of the "Prâna"), then and then only the "OM" can function as the real 'MANTRA'. Any word can thus serve the function of 'MANTRA' if the frequency of the pronounced word attains the frequency of the "Prâna" or the original frequency of ONKAR [i.e. "NADA BRAMHAN"].

When it is possible to create an impression on the mind by repeated recitation of $\mathrm{OM}$ in a purpose to express the fact that the $\mathrm{OM}$ is nothing but the name or representation of the Almighty God, then and then only it is called 'ONKARJAPA'. JAPA is the active process that causes mind to arrive at the primary field representing universal consciousness. Thus consciousness reveals its manifestation to our existence or self-entity through the JAPA. JAPA enforces mind to go to its origin.

\section{Super-Consciousness as Expressed by Pal [31]}

The network of time, space and causation gives rise to the 'Name and Form' called Mâyâ by the Vedanta as expressed by Vivekananda [32]. Mâyâ is a simple statement of facts of the universe, of how it is going on; what we are and what we see around us, although the oldest idea of Mâyâ was the sense of delusion. The world is an illusion due to Mâyâ. No one can go out of one's self. No man can go beyond the limits that have been put upon him by the laws of time, space and causation, the network of which is called Mâyâ. The vanishing of time means the vanishing of one of the constituents of Mâyâ. This Mâyâ itself, in turn, is responsible for the manifestation of this relative world. If one at all likes to go beyond this relative world of Mâyâ in order to arrive at

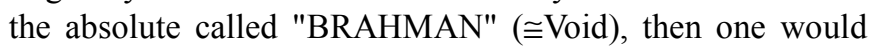
have to adopt the method of meditation for concentrating the mind (to deactivate or control the quantum mechanical activities of these TCP and TRP) in order to achieve the state of "super-consciousness": SAMADHI. At the superconscious state the Yogi (Meditator) unifies himself with the universal soul ( $\cong$ Void).

The super-conscious state is as good as the void ( $\cong$ soul) that is a source of infinite energy. It is obvious that although the super-consciousness and unconsciousness, the two extreme states of consciousness, apparently appear to be the same in nature, yet there is really a heaven and hell difference. In the super-conscious state the quantum mechanical activities of TCP and TRP are absolutely controlled for which there is an apparent absence of functional mind leading to the absence of any sign of 'life' as it is exhibited by any real 'YOGI' (meditator) who can 'recharge' himself to the 'life' function again as per his own desire.

\section{What is Will-Force?}

What is will-force/will-power? Will $\equiv$ Desire. Whose will or desire it is? It is the will/desire of the Prâna. The sum-total 
of the energy displayed in the universe is called Prâna indicated by Vivekananda [28]. This Prâna is usually thought to be the 'universal power'. The Prâna is the gross origin of all the fundamental fields including the 'vital living force' which controls all the psychological as well as the physiological functions of all living beings of the universe. TCP is the force-carrying particle of the original thought force $\left(T_{F}\right)$ which is the origin of all the existing natural fields. Thus, this "Prâna" is more or less equivalent to the original thought force $\left(\mathrm{T}_{\mathrm{F}}\right)$ which is carried by TCP in the inherent presence of TRP.

The action of "Prâna" can be controlled through the 'Prânâyâma', the breathing exercises. The breathing exercises bring about regulation of breathing, rhythmic action of the Prâna. 'Prânâyâma' means the control of Prâna indicated by Vivekananda [28].

Pal [30] expressed: It is to be noted that the "PRANABA" / 'ONKAR' (OM) itself is the so-called "NADA BRAMHAN". Any pronounced 'word' has its origin to the 'PRANABA' / 'ONKAR' (OM) [i.e. "NADA BRAMHAN"]. And every pronounced 'word' ends in the vibration of 'PRANABA' / 'ONKAR' (OM). The 'PRANABA'/ 'ONKAR' (OM) is a word as well as a 'MANTRA'.The OM, mind and the effort to arrive at the field of consciousness should vibrate in a line so that there should be a resonance. It appears that UTF (universal thought frequency) $\cong$ frequency of the TCP $\cong$ frequency of the "Prâna" = $7.466 \times 10^{10} \mathrm{cps} \cong$ frequency of ONKAR $(\mathrm{OM})$.

As the "Prâna" is the grosser form of the original thought force $\left(\mathrm{T}_{\mathrm{F}}\right)$, so it is apparent that the frequency of the TCP frequency of the "Prâna" $=7.466 \times 10^{10} \mathrm{cps} \cong$ frequency of ONKAR (OM) (i.e. "NADA BRAMHAN").

It is to be understood that the "PRANABA" itself is the socalled "NADA BRAMHAN". It is apparent that the original frequency of ONKAR (OM) should have the same universal thought frequency (UTF) that, in turn, is the same frequency of TCP itself that is found to be $7.466 \times 10^{10} \mathrm{cps}$. When the frequency of pronounced "OM" attains its original frequency that, in turn, is the frequency of TCP (or the frequency of the "Prâna"), then and then only the "OM" can function as the real 'MANTRA'. Any word can thus serve the function of 'MANTRA' if the frequency of the pronounced word attains the frequency of the "Prâna" or the original frequency of ONKAR [i.e. "NADA BRAMHAN"].

In short, it is found that

The frequency of the TCP $\cong$ frequency of the "Prâna" $=7.466 \times 10^{10} \mathrm{cps} \cong$ frequency of ONKAR (OM) [i.e."NADA BRAMHAN"].

Will-force/will-power is the force that can be achieved by concentrating the mind through the utilization of Prâna, of course, with a definite specific desire in mind. Consciousness can be elevated to super-conscious-state with the help of willforce along with the ONKAR-JAPA (or NAM-JAPA). This ONKAR is nothing but the frequency of Prâna (三 Frequency of TCP). Will-force is a parameter of mind. Will-force owes its origin to the mind. This mind owes its origin to the Universal Mind (UM). Strength of will-force is dependent on the strength of power to concentrate the mind. Will-force assists consciousness (i.e. the functional state of mind) to arrive at the super-conscious state by concentrating the mind through the utilization of Prâna.

Will-force/Will-power $\neq$ Super-consciousness

\section{Characteristics of Soul ( $\cong$ VOID), Consciousness, Mind and Brain}

Pal et al [3] showed that these TCP and TRP, the constituents of the UM and the ultimate constituents of any matter as well as any mind are conceived here to be originated from the eternal Void at the Big Bang to evolve the space-time continuum and the UM along with the universal consciousness.

Atman $(\cong$ Soul $) \cong$ BRAHMAN $($ ABSOLUTE $) \cong$ Void of modern science (This void is the source of infinite energy as it is filled up with infinite pairs of virtual particles and antiparticles).

Pal et al [3] explained that the eternal Void has been covered by the mind to function as the Soul of the individual being. In the universe, behind the UM, there is a Soul ( $\cong$ VOID). In the individual, behind the individual mind (which is a constituent of the UM), there is also a Soul ( $\cong$ VOID).

Pal et al [3] explained that Soul ( $\cong$ Void) being the master ruler of the body exerts its functions through the finer instrument called mind. The mind (with the help of TCP and TRP) exerts its functions through the brain and spinal cord (CNS) along with the other parts of the nervous system (PNS along with ANS) in the biological systems in order to grasp this physical universe, of course, in the inherent presence of consciousness. This consciousness itself is acting as an interlinking agent between the animate and inanimate through the quantum mechanical activities of these TCP and TRP. Consciousness is defined here as the 'self-organized' capability of any living being to activate TCP and TRP, the ultimate constituents of any matter as well as any mind. This consciousness, in turn, is the quantized energy $\left(\boldsymbol{\varepsilon}_{T}\right)$ of TCP.

Any matter as well as the individual mind is constituted by these TCP and TRP that, in turn, are originated from the same eternal Void. Thus the individual mind is operated by these TCP and TRP that, in turn, are ultimately governed by the same eternal Void. The individual mind being a constituent of the UM has covered the eternal Void to serve the role of individual Soul. This eternal Void is thus the common source and the source is still with us indicated by Bhaumik [4]. This Void serves the role of Soul being covered by the mind.

\section{Discussion and Conclusion}

\subsection{Discussion}

I have developed a consciousness model involving TCP, TRP and thought force $\left(\mathrm{T}_{\mathrm{F}}\right)$ in a purpose to form a possible gross bridge between mind and matter, present physics and cognitive science, psychology and natural sciences, classical 
physics and quantum physics. Pal [5] explained the testability for the existence of TCP and TRP along with the Thought force $\left(\mathrm{T}_{\mathrm{F}}\right)$ through the article entitled, "Existence of thought force and its characteristics". Pal [5] mentioned several experimental results to signify the existence of quantum mechanical activities of these TCP and TRP, the ultimate constituents of matter and mind in the inherent presence of thought force $\left(\mathrm{T}_{\mathrm{F}}\right)$ in vitro and the thought force $\left(\mathrm{T}_{\mathrm{F}}\right)$ in vivo.

Covering many enigmatic specific critical aspects of modern science I have published 28 research articles in different Journals including American Journal of Modern Physics, American Journal of Physics and Applications and American Journal of Physical Chemistry: All these Journals are open access Journals of Science Publishing Group.

These articles, in my view, can provide plausible guidelines to tackle many present day scientific enigmas through this consciousness model.

\subsection{Conclusion}

The power of the mind to influence other minds by the will-force in the presence of consciousness leading to superconsciousness is expressed here.

The existence of TCP, TRP and thought force $\left(\mathrm{T}_{\mathrm{F}}\right)$ in vitro and thought force $\left(\mathrm{T}_{\mathrm{F}}\right)$ in vivo may provide plausible guidelines to lucidly explain the evolution of the universe with fundamental laws of natural science like physics, chemistry and biology (with consciousness).

It appears that the standard model of physics is to be correctly tuned by ascertaining the constituents of quarks and leptons in the presence of unified field in order to form a possible gross bridge between mind and matter, present physics and cognitive science, psychology and natural sciences, classical physics and quantum physics.

\section{References}

[1] D. Pal and A.U. De, Physics of consciousness and its model may provide guidelines to solve Many scientific problems. Neuroquantology 1: 17-28(2004)

[2] D. Pal and A.U. De, Consciousness model: Significance of thought-carrying particles and thought-retaining particles in quantum measurement as well as cognitive problem. Neuroquantology 2: 115-116 (2005)

[3] D. Pal and A.U. De, The cosmic microwave background radiation temperature signifying the existence of the thoughtcarrying particle, thought retaining particle and thought force. NeuroQuantology 10: Issue3; 428-442 (September 2012)

[4] M. Bhaumik, Code Name GOD. (Penguin Books India Pvt. Ltd., 11 Community Centre, Panchsheel Park, New Delhi 110 017, India) pp. 132-133; 161-162; 167; 171; 177; 183 and 184. 185-186; 89-190; 198 (2006)

[5] Dhananjay Pal, Existence of Thought Force and Its Characteristics, American Journal of Physical Chemistry. Vol. 2, No. 5, 2013, pp. 94-104. doi: 10.11648/j.ajpc.20130205.13

[6] V. F. Weisskopf, The Origin of the Universe, The World of Physics, (Simon and Schuster, 1230 Avenue of Americas, New
York 10020) 3, pp. 10 and 314 (1987)

[7] D. Pal, Existence of universal consciousness and its characteristics. Accepted for publication In 2014 International Conference on Advanced Education and Management (ICAEM2014) Beijing, China (2013)

[8] I. Prigogine and G. Nicolis, Self-Organization in NonEquilibrium Systems. (Wiley 1977) ISBN 0471024015.

[9] R. Nelson, Director, Global Consciousness Project, Princeton, New Jersey. (2009) rdnelson@princeton.edu

[10] D. Radin, The Conscious Universe: The Scientific Truth of Psychic Phenomena. (Harper Edge) (1997) ISBN 0-06251502-0.

[11] R. Penrose, Shadows of the Mind: A Search for the Missing Science of Consciousness. (Oxford University Press) (1994)

[12] W. Van De Bogart, Earth portals: Exploring New Metaphors of Consciousness 1993 willard@earthportals.com

[13] S. Vivekananda, Soul, Nature and God (Linga Sharira or Sukshma Sharira). The complete works of Swami Vivekananda. (Advaita Ashrama, India) 2: pp-424 and 438; ibid. The real and apparent man (Samaskaras) 2: pp-268-269 (1989)

[14] S. Parnia, Do reports of consciousness during cardiac arrest hold the key to discovering the nature of consciousness? Medical Hypotheses 69(4): 933-937 (2007)

[15] P van. Lommel, R. Wees, V. Meyers and I. Elfferich, NearDeath Experience in Survivors of Cardiac Arrest: A prospective Study in the Netherlands. The Lancet (9298): 2039-45 (2001)

[16] P. Fenwick, S. Parnia, D.G. Waller, and R. Yeates, A qualitative and quantitative study of the incidence, features and aetiology of near-death experiences in cardiac arrest survivors. Resuscitation 48: 149-156 (2001)

[17] M. Beauregard and D. O'Leary, The spiritual brain: A neuroscientist's case for the existence of the soul. (Harper Collins Publishers) (2008)

[18] M. Beauregard and V. Paquette, Neural correlates of a mystical experience in Carmelite nuns. Neuroscience Letters 405, 186-190 (2006)

[19] L. Cosmides and J. Tooby J. From evolution to behavior: Evolutionary psychology as the missing link. (In J. Dupre (Ed.), The latest on the best: Essays on evolution and optimality, Cambridge,MA, The MIT Press. (1987)

[20] L. Cosmides, J. Tooby, J. Barkow, The adapted mind: Evolutionary psychology and the Generation of culture. (New York: Oxford University Press. 1992)

[21] L. Cosmides and J. Tooby, Beyond intuition and instinct blindness: Towards an evolutionary rigorous cognitive science. Cognition; 50 (1-3): 41-77 (1994)

[22] BD. Josephson. Biological Utilization of Quantum Nonlocality. Foundations in Physics, Vol. 21; 197- 207. (1991)

[23] Swami Vivekananda. The Power of the Mind, The complete works of Swami Vivekananda, Advaita Ashrama. 2: p-10-23 (1989) 
[24] Dhananjay Pal, Interpretation of Information Processing and Mode of Perception Through the Consciousness Model Involving Though-Carrying Particle (TCP), Thought Retaining Particle (TRP) and Thought Force (TF) in vitro and Thought Force (TF) in vivo, American Journal of Modern Physics. Vol. 2, No. 6, 2013, pp. 341-349. doi: 10.11648/j.ajmp.20130206.21

[25] Swami Vivekananda. The Importance of Psychology, The complete works of Swami Vivekananda, Advaita Ashrama. 6: p-28-32(1989)

[26] Adhikari Srikanta Dash and Shri Suvashisa Rana. Methods of Study in Indian Psychology. This paper was presented at Psychology: The Indian Contribution, National Conference on Indian Psychology, Yoga and Consciousness, Organized by the Indian Council of Philosophical Research at the Sri Aurobindo International Centre of Education, Pondicherry, India, (10-13 December 2004)

[27] Fritjof Capra. Uncommon Wisdom. Flamingo, An Imprint of Harper-Collins Publishers. p-159 and 216-217. (1989)

[28] Vivekananda. RAJA-YOGA, The complete works of Swami Vivekananda, Advaita Ashrama. 1: p-223; ibid.; PRANA, 1: p-
147- 173. ibid.; The Cosmos (the Microcosm); 2: p-212-225 (1989)

[29] Dhananjay Pal, Possible Bridging the Classical Physics and Quantum Physics through Consciousness, American Journal of Modern Physics. Vol. 2, No. 6, 2013, pp. 322- 329. doi: 10.11648/j.ajmp.20130206.18

[30] Dhananjay Pal, The Healing Power of Mind and Theoretical Approach to Develop a So- Called Panacea through the Consciousness Model, American Journal of Modern Physics. Vol. 2, No. 6, 2013, pp. 402-416. doi: 10.11648/j.ajmp.20130206.28

[31] Dhananjay Pal, Relation of Space-Time Continuum with Energy in the Presence of Consciousness and SuperConsciousness, American Journal of Physics and Applications. Vol. 1, No. 3, 2013, pp. 67-79. doi: 10.11648/j.ajpa.20130103.14

[32] Vivekananda, Mâyâ and Illusion, "The complete works of Swami Vivekananda", (Advaita Ashrama, 5 Dehi Entally Road, Calcutta-700 014, 1989) 2: P-90. Mâyâ and Freedom, ibid.; 2: p-121 